\title{
Factors affecting soluble solids content of muskmelon (Cucumis melo L.)
}

\author{
G. W. H. Welles and K. Buitelaar \\ Glasshouse Crops Research Station, P.O. Box 8, NL 2670 AA Naaldwijk, Nether- \\ lands
}

Received 11 January 1988; accepted 21 March 1988

Key words: muskmelon, Cucumis melo L., soluble solids, fruit load, night temperature, leaf area, cultivars, ripening stage.

\begin{abstract}
In a series of five experiments, performed during spring, summer and autumn in heated glasshouses, effects of fruit load, leaf area, night temperature, cultivar and ripening stage on the soluble solids content (SSC) of muskmelon (Cucumis melo L.) were studied. Except fruit load, all factors proved to affect SSC. In all experiments the maturation period of the fruit, i.e. the period between fruit set and harvest, was positively correlated with SSC. In order to obtain fruits with high SSC, it seems important to aim at a low rate of fruit growth, i.e. a long maturation period. Low night temperatures in the period of fruit growth, a high leaf area, harvesting of ripe fruits and selecting slow-ripening cultivars may contribute to fruits with high SSC.
\end{abstract}

\section{Introduction}

Sweetness is an important factor in the appreciation of the flavour of muskmelon. Soluble solids content (SSC), expressed as percentage of fresh weight, shows high positive correlation with sugar content and is therefore generally accepted as an important quality characteristic (Aulenbach \& Worthington, 1974). In the past, many experiments have been done to investigate the main factors affecting concentration of soluble solids in melon fruits. Evidence has been presented for the impact of factors such as mineral nutrition (Brantley \& Warren, 1961; Jacob \& White-Stevens 1941; Flocker et al., 1965), soil moisture (Wells \& Nugent, 1980), genetic factors (Lippert \& Legg, 1972), weather conditions (Brantley \& Warren, 1961; Bouwkamp et al., 1978) and growth regulators (Bosland et al., 1979).

Under Dutch conditions, a large variation in SSC between fruits of individual plants is observed. Besides this, in practice it seems very difficult to increase overall SSC to a level competitive with that of fruits from the South of Europe.

In order to quantify the effects of various growing conditions, growing methods 
and cultivars on fruit quality (SSC), several experiments were conducted during the years 1979-1985.

\section{Materials and methods}

\section{Ripening stage}

The effect of ripening stage, i.e. fruit colour at picking, on SSC of muskmelon ( $C u$ cumis melo L.) was studied in an experiment conducted in spring and summer of 1979. Two cultivars, Haon and Polidor, were planted in two replicates on 10 May. On 20 July, a random sample of 10 fruits of each cultivar and colour stage was harvested. A scale for colour and ripening stage, ranging from 1-10 was used. Four stages were examined, viz. 2, 4, 6 and 8, which correspond with the colours green, green/yellow, yellow/green and yellow, respectively.

\section{Cultivars}

In order to assess differences between cultivars with respect to SSC, four and five cultivars were grown in a heated glasshouse during spring and summer of 1980 and 1981, respectively. Each experiment encompassed two replicates. Planting dates were 21 April and 29 March, respectively. At harvest between early June and the end of July, SSC was measured regularly in at least 20 fruits per cultivar.

\section{Fruit load}

The effect of fruit load on SSC was studied in an experiment carried out in spring and summer 1980 with cv. Haon. After planting (21 April) at fruit set the number of fruits per plant was kept at 2, 4, 6 or 8 by means of pruning. In order to achieve sufficient numbers of fruits per plant, two main stems per plant were maintained.

Treatments were performed in four replicates. Of every fruit on each plant (32 plants per treatment) records were made of dates of fruit set and of picking, of fruit position and of SSC at harvest.

\section{Leaf area}

In autumn 1981, an experiment was set up in which four levels of leaf area were created at fruit set by means of trimming and topping of side shoots, after stopping the main stem at the wire. Treatments were in four replicates. $\mathrm{Cv}$. Haon was planted on 20 July, allowing one main stem to grow upright. At fruit set, three fruits per plant were maintained. Of each fruit, dates of fruit set and of picking were recorded. During the harvest period, SSC was measured of all fruits. Leaf area was measured with a leaf area meter (type Licor) on 8 September. Because leaf area and fresh weight of individual leaves showed a high correlation $(r=0.99)$, fresh weight of leaves of individual plants at harvest (12 October) could be transformed to leaf areas per plant and hence per treatment. 


\section{Night temperatiure}

Four night temperature treatments were performed in three replicates in a spring experiment in 1984. Cultivars Haon and Makdimon were planted on 16 March. Night temperature was lowered 47 days after planting from $21{ }^{\circ} \mathrm{C}$ to $13,15,18$ and $21^{\circ} \mathrm{C}$. At that time all plants bore fruits with an average diameter of approx. $10 \mathrm{~cm}$. Of each fruit, date of fruit set and picking as well as SSC at harvest were assessed.

In all experiments mentioned above, SSC was measured with an Abbe refractometer on juice, squeezed from a plug of $4 \mathrm{~cm}$ length, reaching the centre of the fruit. SSC was expressed as weight percentage of soluble solids. This percentage of soluble solids equalizes the concentration of sucrose in an aqueous solution which has the same refractive index as the product analysed, in specified conditions of preparation and temperature. This concentration is expressed as a percentage by mass (Anon., 1978). Measurements were done at full ripe fruits, i.e. colour stages 6-8, unless stated otherwise.

\section{Results}

\section{Ripening stage}

In cv. Haon harvested green fruits (colour stage 2) showed significantly lower SSC than riper fruits (Table 1). Harvesting immature green fruits seems to have more adverse effects on quality with $\mathrm{cv}$. Haon than with $\mathrm{cv}$. Polidor. Table 1 also makes clear that there may be important differences in SSC between cultivars. This becomes even more obvious from results of cultivar trials performed in 1980 and 1981.

\section{Cultivars}

Tested cultivars Haon, Galia, Chaca and Aroma had mean SSC values of 8.4, 6.8, 5.8 and 3.2, respectively, in 1980. In 1981, cultivars Haon, Green Delica, Trapio, Marina and Marble White showed SSC values of 9.0, 12.6, 9.2, 10.5 and 15.4, respectively. Cultivar Aroma yielded fruits of poor quality, while Marble White and Green Delica produced fruits with high SSC.

Table 1. SSC (in \%) of cultivars Haon and Polidor harvested at 4 different ripening stages.

\begin{tabular}{lll}
\hline Ripening stage & \multicolumn{2}{l}{ Soluble solids content (SSC) } \\
\cline { 2 - 3 } & Haon & Polidor \\
2 & 5.8 & 4.8 \\
4 & 8.7 & 5.9 \\
6 & 9.7 & 5.3 \\
8 & 9.5 & 5.8 \\
LSD $(P<0.05)$ & 1.5 & 1.6 \\
\hline
\end{tabular}


Table 2. Corrclation matrix. means and standard deviations of plant characteristics determined in the fruit load experiment. Number of plants: 251 ; number of fruits: $1007 . \mathrm{SSC}=$ soluble solids content ( $/ \mathrm{C})$; $\mathrm{PL}=$ fruit load (number of fruits); $\mathrm{MP}=$ maturation period (days) $\mathrm{H}=$ date of harvest (day number): $\mathrm{PO}=$ position of fruit on plant ( $\mathrm{cm}$ above soil level).

\begin{tabular}{lllrrr} 
Characteristic & SSC & PL & MP & H & PO \\
SSC & 1.000 & $-0.314^{*}$ & $0.527^{*}$ & $0.382^{*}$ & -0.090 \\
PL & - & 1.000 & $-0.262^{*}$ & -0.155 & $0.222^{*}$ \\
MP & - & - & 1.000 & $0.830^{*}$ & -0.154 \\
H & - & - & - & 1.000 & -0.098 \\
PO & - & - & - & - & 1.000 \\
Mean & 9.8 & 4.8 & 52.4 & 200.5 & 97.9 \\
s.d. & 1.9 & 1.5 & 3.9 & 5.3 & 20.0 \\
\hline
\end{tabular}

$* P<0.01$

\section{Fruit load}

Because of poor fruit set. the four levels of fruit load resulted in 2.0, 3.9, 5.2 and 5.6 fruits per plant. In Table 2, correlation coefficients between all plant characteristics recorded are given. As can be seen from this table, SSC is clearly affected by fruit load. From the characteristics measured, only maturation period of fruits proved to be a major factor in explaining differences in SSC between individual fruits. More than $27 \%$ of the total variability in SSC could be accounted for by differences in maturation period of fruits. Variation in maturation period was strongly related with differences in harvesting dates $(r=0.83)$. However, multiple regression showed that factors such as day of harvest and position of fruits on the plants did not influence SSC significantly (Table 2). The following equation could be obtained: $\mathrm{SSC}=0.248 \times \mathrm{MP}-0.117 \times \mathrm{PL}+2.132$. Hence, the factor fruit load played only a minor role with respect to differences in SSC.

\section{Leaf area}

In Table 3, results of treatments affecting leaf area in the 1981 experiment are given. The leaf area of the control treatment is more or less three times higher than in the treatments where only three side shoots are maintained.

SSC decreases significantly with lower leaf area. When all side shoots are kept without topping (Treatment 1), both mean SSC and mean maturation period are increased significantly.

Maturation period is not affected by the number of topped side shoots maintained, nor by the absence of the leaf nearest to each fruit. However, topping and removing side shoots clearly lowers SSC, while the absence of the fruit leaf is again of no importance (Treatments 3 and 4 versus Treatment 2). 
Table 3. Estimated leaf areas of plants, mean SSC and mean maturation period of fruits from 4 treatments, differing in trimming and topping of side shoots.

\begin{tabular}{|c|c|c|c|}
\hline Treatment & $\begin{array}{l}\text { Estimated leaf } \\
\text { area per plant } \\
\left(\times 10^{4} \mathrm{~cm}^{2}\right)\end{array}$ & $\begin{array}{l}\text { Mean SSC } \\
(\%)\end{array}$ & $\begin{array}{l}\text { Maturation } \\
\text { period (days) }\end{array}$ \\
\hline 1. No topping of shoots & 4.73 & 11.9 & 49 \\
\hline $\begin{array}{l}\text { 2. Topping of all side } \\
\text { shoots at } 3 \text { leaves }\end{array}$ & 3.21 & 10.6 & 46 \\
\hline $\begin{array}{l}\text { 3. Maintaining only } 3 \text { side } \\
\text { shoots, topping at } 3 \text { leaves }\end{array}$ & 1.70 & 8.1 & 45 \\
\hline $\begin{array}{l}\text { 4. As treatment no } 3 \text {. and } \\
\text { removing of leaf above } \\
\text { the fruit on every side shoot }\end{array}$ & 1.52 & 8.2 & 46 \\
\hline $\operatorname{LSD}(P<0.05)$ & 0.87 & 0.7 & 2.6 \\
\hline
\end{tabular}

Significant correlations were found between leaf area per plant and SSC $(r=$ $0.56 ; n=64)$ and between maturation period and SSC $(r=0.624 ; n=386)$. Significant differences in mean fruit weight between treatments could not be found.

\section{Night temperature}

The effect of low night temperatures after fruit set on SSC and maturation period of individual fruits in the 1984 experiment is demonstrated in Table 4. Low night temperature seems to have more effect on maturation period than on SSC of the fruit. Decreasing temperatures delayed the date of harvest. Although no significant effect of night temperature on mean SSC could be found, the results in Table 4 seem to indicate a negative effect of higher night temperatures. Due to the large variation in SSC between replicates, a significant relation between SSC and night temperature could not be demonstrated.

In Fig. 1, relations between maturation period and SSC of individual fruits in the

Table 4. Realized night temperatures in the period between 47-128 days after planting, mean SSC and mean maturation period per treatment.

\begin{tabular}{llll}
\hline $\begin{array}{l}\text { Temperature } \\
\text { treatment }\left({ }^{\circ} \mathrm{C}\right)\end{array}$ & $\begin{array}{l}\text { Realized } \\
\text { temperatures }\left({ }^{\circ} \mathrm{C}\right)\end{array}$ & $\begin{array}{l}\text { Mean SSC } \\
(\%)\end{array}$ & $\begin{array}{l}\text { Maturation period } \\
(\text { days })\end{array}$ \\
12 & 14.0 & 11.3 & 50 \\
15 & 15.6 & 11.1 & 49 \\
18 & 17.4 & 10.9 & 46 \\
21 & 20.4 & 9.9 & 43 \\
LSD $(P<0.05)$ & & 2.4 & 6 \\
\hline
\end{tabular}




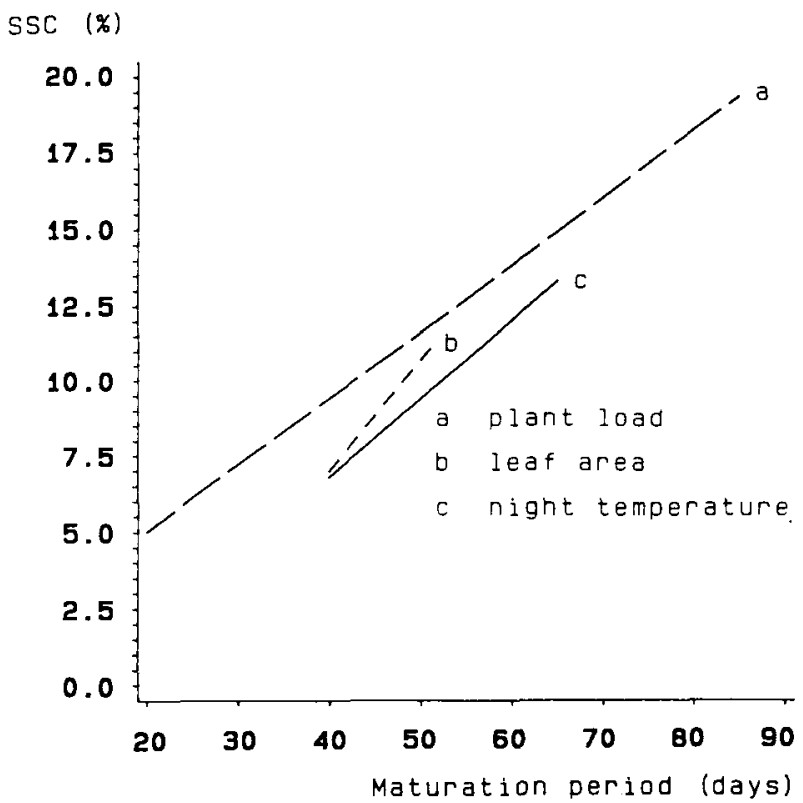

Fig. 1. Relationships between maturation period and SSC of muskmelon fruits obtained in 3 experiments. Regression equations: fruit load (a): $y=0.26 x-3.63$; leaf area (b): $y=0.37 x-7.82$; night temperature (c): $y=0.22 x+0.61$. Correlation coefficients $r=0.527(n=1007), r=0.624(n=385)$ and $r=$ $0.681(n=557)$, respectively.

fruit load, leaf area and night temperature experiments are summarized. As can be seen, sampling period was longest in the fruit load and shortest in the leaf area experiment. In both spring experiments (factors fruit load and night temperature; see Fig. 1), increase in maturation period with 10 days resulted in an increase of SSC with more than $2 \%$. In the autumn experiment this increase was almost doubled.

\section{Discussion and conclusions}

From all factors studied in these experiments, length of maturation period of individual fruits gave the highest correlation with SSC. Between 27 and $46 \%$ of total variation in SSC could be attributed to differences in length of maturation period. Maturation period of fruits may be influenced by many environmental and genetic factors. In our experiments, the maturation period of fruits was influenced by the factors cultivar, leaf area and night temperature.

A higher leaf area of plants will in general increase their photosynthetic capacity and will - at a given level of fruit load - lead to higher SSC levels in the fruits. Higher production of assimilates resulted in our experiments in an increased maturation period, i.e. later date of harvest.

It is possible that another factor is involved, explaining increased maturation 
period and SSC levels of fruits of plants with high leaf area. The results of experiments of Sawamura et al. (1978) support the theory of Burg et al. (1965) in which unstable ripening-inhibiting substance(s), fed from the vegetative parts into the developing fruits, increase the threshold value of ethylene action in the fruits. Since processes leading to senescence of tomato and melon fruits are very similar (Hulme, 1971), presence of ripening-inhibiting substance(s) could explain delayed ripening observed on plants with high leaf area.

In the fruit load and night temperature experiment it was observed (results not given) that a more vigorous plant growth (i.e. plants with high leaf area) occurred at a low level of fruit load and at low night temperature. Besides increased net photosynthesis, resulting in higher SSC levels in the fruits under these conditions, increased levels or activity of this ripening-inhibiting substance in the fruit load and night temperature experiment might explain the results observed. For at a high level of production of assimilates, available for the individual fruit, one may suppose that with a longer 'hanging time' on the plant (increased maturation period), the increase of SSC will reach higher maximum levels at harvest.

Differences in plant vigour between cultivars might at least be partly responsible for differences in mean SSC. We have experienced that cultivars as Green Delica and Marble White are vigorous and yield slow-ripening fruits with high SSC. Ripening stage of fruits at harvest seems to play only a minor role in explaining differences in mean SSC between cultivars, since fruits of all cultivars were picked at colour stage 6 or higher.

In conclusion, factors as low night temperature, high leaf area and choice of slowripening cultivars will contribute to increase the maturation period, and are important when aiming at the production of fruits with high SSC. However, differences in mean SSC between individual fruits still have to be explained by other factors. Therefore, more research is needed to reduce variability in SSC and ensure a uniform quality at harvest.

\section{References}

Anon. 1978. Fruit and vegetable products. Determination of soluble solids - Refractometric method. International Organization for Standardization, ISO 2173, $4 \mathrm{pp}$.

Aulenbach, B. B. \& J. T. Worthington, 1974. Sensory evaluation of muskmelon: is soluble solids content a good quality index. HortScience 9: 136-137.

Bosland, J. M., D. L. Hughes \& M. Yamaguchi, 1979. Effects of glyphosine and triacontanol on growth, yield and soluble solids content of 'PMR-45' muskmelons. HortScience 14: 729-730.

Bouwkamp, J. C., F. F. Angell \& F. D. Schales, 1978. Effects of weather conditions on soluble solids of muskmelon. Scientia Horticulturae 8: 265-271.

Brantley, B. B. \& G. F. Warren, 1961. Effect of nitrogen nutrition on flowering, fruiting and quality in the muskmelon. Proceedings of the American Society for Horticultural Science 77: 424-431.

Burg, S. P. \& E. A. Burg, 1965. Ethylene action and the ripening of fruits. Science 148: 1190-1196.

Flocker, W. J.. J. C. Lingle, R. M. Davis \& R. J. Miller, 1965. Influence of irrigation and nitrogen fertilization on yield, quality and size of cantaloupes. Proceedings of the American Society for Horticultural Science 86: 424-432.

Hulme, A. C.. 1971. The biochemistry of fruits and their products. Vol. 2, 285 pp., Academic Press, London/New York. 


\section{G. W. H. WELLES AND K. BUITELAAR}

Jacob, W. L. \& R. H. White-Stevens, 1941. Studies in the minor element nutrition of vegetable crops plants. II. The interaction of potash, boron and magnesium upon the flavor and sugar content of melons. Proceedings of the American Society of Horticultural Science 39: 369-374.

Lippert, L. F. \& P. D. Legg, 1972. Appearance and quality characters in muskmelon fruit evaluated by a tencultivar diallel cross. Journal of the American Society of Horticultural Science 97: 84-86.

Sawamura, M., E. Knegt \& J. Bruinsma, 1978. Levels of endogenous ethylene, carbon dioxide, and soluble pectin, and activities of pectin methylesterase and polygalacturonase in ripening tomato fruits. Plant \& Cell Physiology 19: 1061-1069.

Wells, J. A. \& P. E. Nugent, 1980. Effect of high soil moisture on quality of muskmelon. HortScience 15: 258-259. 